\title{
Immunogenicity and In Vivo Efficacy of Recombinant Plasmodium falciparum Merozoite Surface Protein-1 in Aotus Monkeys
}

\author{
Sanjai Kumar,* Anjali Yadava,* David B. Keister,* \\ Jing Hui Tian,* Michael Ohl, ${ }^{\dagger}$ Kathy A. Perdue-Greenfield, ${ }^{\neq}$ \\ Louis H. Miller,* and David C. Kaslow* \\ *Laboratory of Malaria Research, National Institute of Allergy and \\ Infectious Diseases, National Institutes of Health, Bethesda, Maryland, \\ U.S.A. \\ ${ }^{+}$Howard Hughes Medical Institute-National Institutes of Health \\ Research Scholar Program, Chevy Chase, Maryland, U.S.A. \\ ${ }^{\ddagger}$ Veterinary Resources Program, National Center for Research \\ Resources, National Institutes of Health, Bethesda, Maryland, U.S.A.
}

\begin{abstract}
Background: The carboxy-terminus of the merozoite surface protein-1 (MSPl) of Plasmodium falciparum has been implicated as a target of protective immunity.

Materials and Methods: Two recombinant proteins from the carboxy-terminus of MSP1, the $42 \mathrm{kD}$ fused to GST $\left(\mathrm{bMSPl}_{42}\right)$ and the $19 \mathrm{kD}\left(\mathrm{YMSP}_{19}\right)$, were expressed in Escherichia coli and secreted from Saccharomyces cerevisiae, respectively. To determine if vaccination with these recombinant proteins induces protective immunity, we conducted a randomized, blinded vaccine trial in two species of Aotus monkeys, A. nancymai and $A$. vociferans. After three injections using Freund's adjuvant, the monkeys were challenged with the virulent Vietnam Oak Knoll (FVO) strain of $P$. falciparum.

Results: All three control monkeys required treatment by Day 19. Two of three monkeys vaccinated with bMSPl $_{42}$ required treatment by Day 17 , whereas the third monkey controlled parasitemia for 28 days before
\end{abstract}

requiring treatment. In contrast, both of the A. nancymai vaccinated with $\mathrm{YMSP}_{19}$ self-resolved an otherwise lethal infection. One of the two yMSP1 ${ }_{19}$-vaccinated $A$. vociferans had a prolonged prepatent period of $>28$ days before requiring treatment. No evidence of mutations were evident in the parasites recovered after the prolonged prepatent period. Sera from the two A. nancymai that self-cured had no detectable effect on in vitro invasion.

Conclusions: Vaccination of $A$. nancymai with yMSP1 19 induced protective immune responses. The course of recrudescing parasitemias in protected monkeys suggested that immunity is not mediated by antibodies that block invasion. Our data indicate that vaccine trials with the highly adapted FVO strain of $P$. falciparum can be tested in $A$. nancymai and that MSPI $_{19}$ is a promising anti-blood-stage vaccine for human trials.

\section{INTRODUCTION}

Malaria is a problem of serious and increasing proportions. Effective antimalarial vaccines offer hope in reducing morbidity and mortality from

Address correspondence and reprint requests to: David C. Kaslow, Laboratory of Malaria Research, Building 4, Room 126, NIH, Bethesda, MD 20892, U.S.A. malaria in such a deteriorating situation. A number of parasite molecules from various stages of the parasite's life cycle have been suggested as vaccine candidates. One of the most studied antigens from the asexual blood stages of the life cycle is the $195-\mathrm{kD}$ merozoite surface protein-1 (MSP1) (1). MSP1 is processed by proteolytic cleavage into a series of distinct fragments $(2,3)$. 
These fragments remain associated through noncovalent linkages and are attached to the merozoite surface by the carboxy-terminal $42-\mathrm{kD}$ fragment $\left(\mathrm{MSPl}_{42}\right)$. Around the time of red blood cell (RBC) invasion by merozoites, $\mathrm{MSP}_{42}$ is further processed into a $33-\mathrm{kD}$ soluble polypeptide and a membrane-bound 19-kD carboxyterminal fragment $\left(\mathrm{MSPl}_{19}\right)$. MSP1 $1_{19}$, which consists of two cysteine-rich EGF-like domains and a GPI anchor, continues to be present on ring forms in newly invaded RBCs $(4,5)$. Several lines of evidence suggest that the carboxy-terminal fragments of MSPl are targets of protective immunity: immunization/challenge studies with recombinant MSP $_{19}$ in a murine model $(6,7)$; and in vitro inhibition of erythrocyte invasion with anti-MSPI 19 monoclonal (4) and anti-MSP1 42 polyclonal antibodies (8).

The mechanism of protective immunity in humans is presently unclear: antibodies, cytokines, and antibody-dependent cellular inhibition have all been implicated. Therefore, until the mechanism(s) of in vivo efficacy has been elucidated, in vitro tests are of limited value. Aotus monkey models have been proposed as suitable models for identifying and testing potential vaccine candidates. We tested two recombinant MSPI proteins-one secreted by yeast and the other expressed in bacteria-in two species of Aotus monkeys, A. nancymai and $A$. vociferans. Here, we describe the utility of Aotus monkeys in vaccine trails: $A$. nancymai challenged with the highly virulent Vietnam Oak Knoll (FVO) isolate of Plasmodium falciparum appears to be a sensitive model for testing $\mathrm{MSP}_{19}$ vaccines.

\section{MATERIALS AND METHODS}

\section{Vector Construction, Expression, and Protein Purification of rGST-MSPI ${ }_{42}$}

Primers (sense oligonucleotide 5'-GCGGATC CCAGTAACTACTTCCGTAATTGAT- ${ }^{\prime}$ ' and antisense oligonucleotide 5'-GCGAATTCAAGTTA GAGGAACTGCAGAAAAT-3') were used to clone the $42-\mathrm{kD}$ carboxyl-terminus of the $P$. falciparum FVO strain $\mathrm{MSPl}_{42}$ gene into expression vector pGEX3 under control of the IPTG-inducible ptac promoter. The gene encoding $\mathrm{MSP}_{42}$ was polymerase chain reaction (PCR)-amplified from a plasmid containing the MSPl gene from genomic DNA of the FVO strain (S. Kumar, unpublished). The PCR-amplified $\mathrm{MSPl}_{42}$ was cloned into the EcoRI and BamHI restriction sites of pGEX3, creating a fusion protein between Schistosoma japonicum glutathione S-transferase (GST) and $\mathrm{MSPl}_{42}$ $\left(\mathrm{bMSP}_{42}\right)$. The recombinant plasmid was electroporated into Escherichia coli $\mathrm{DH} 10 \mathrm{~B}$ cells by using a Gene Pulse apparatus (Bio-Rad, Richmond, CA, U.S.A.). Bacterial cultures were grown overnight and then induced by addition of $1 \mathrm{mM}$ IPTG to produce recombinant protein at $37^{\circ} \mathrm{C}$ for $2 \mathrm{hr}$. The cells were harvested and lysed by sonication. Recombinant protein was bound to a reduced glutathione-agarose column (Pharmacia, Piscataway, NJ, U.S.A.) and eluted with $10 \mathrm{mM}$ reduced glutathione (CalBiochem, San Diego, CA, U.S.A.).

\section{Vector Construction, Expression, and Protein Purification of YMSP1 19}

We planned to construct a shuttle plasmid that would secrete from Saccharomyces cerevisiae a fusion protein consisting of the $\mathrm{P} 30$ and $\mathrm{P} 2$ universal helper $\mathrm{T}$ cell epitopes of tetanus toxoid (9) fused to $\mathrm{MSPl}_{19}$. To express $\mathrm{P} 30$, a cassette was made using synthetic oligonucleotides (sense oligonucleotides 5'-CTGGTACCTTTGGATAAAAGAG ACGCTGAAGCTTCTTTGGATAAAAGATTCAACAA CTTCACTGTC- $3^{\prime}$ and $5^{\prime}$-TCTTTCTGGTTGAGAGTTA AGGTCTCCGCCTCCCACCTCGAGAAC- $3^{\prime}$ and antisense oligonucleotides 5'-GTTCTCGAGGTGGGAG GCGGAGACCTTAACTCTCAACCAGAAAGAGACA GTGAAGTTGTTGAA-3' and 5'-TCTTTTATCCAAAG AAGCTTCAGCGTCTCTTTTATCCAAAGGTACCAG$\left.3^{\prime}\right)$ to encode tetanus toxoid amino acids 947-967, FNNFTVSFWLRVKVSASHLE (9). The P2 epitope was also constructed using oligonucleotides (sense 5'-CCGCTCGAGCAATACATTAAGGCTAACTCTAA GTTCATTGGTATTACTGAAGTCGACGAATTCCGG$3^{\prime}$ and antisense 5'-CCGGAATTCGTCGACTTCAGT AATACCAATGAACTTAGAGTTAGCCTTAATGTATT GCTCGAGCGG-3') encoding tetanus toxoid amino acids 830-843, QYIKANSKFIGITE (9). The $\mathrm{MSP}_{19}$ gene fragment (Asn-1631 to Ser-1723) was PCRamplified from a plasmid containing the FVO MSPI gene using the following primers: sense oligonucleotide 5'-CACCTCGAGAACATTTC ACAACACCAA3'; antisense oligonucleotide 5'-CCACTAGTGGTGGT GGTGGTGGTGACTGCAGAAAATACCATC- ${ }^{\prime}$. The cassettes were ligated into pIXY 154 (a gift of V. Price of from Immunex and a derivative of $\mathrm{pADH} 2$ as described in Ref. 10) to create recombinant plasmid $\mathrm{P} 30 \mathrm{P} 2 \mathrm{MSPl}_{19}$. The resultant recombinant plasmid was electroporated into the 2905/6 strain of S. cerevisiae (11). Expression and purification of the recombinant protein were done as described earlier (11). Briefly, $\operatorname{trp}^{+}$recombinant yeast were fermented at 
$25^{\circ} \mathrm{C}$ by fed-batch with $\operatorname{trp}^{-}$selective protein expression medium. The cells were collected $6-18 \mathrm{hr}$ after induction with ethanol. Microfiltered culture supernatant was ultra- and then diafiltered with a $10-\mathrm{kD}$ spiral fiber filter. The protein was recovered by batch binding to Ni-NTA agarose (Qiagen, Chatsworth, CA, U.S.A.) at $4^{\circ} \mathrm{C}$ for $2-18 \mathrm{hr}$. The resin was washed four times with $2 \times$ phosphate buffered saline (PBS). The recombinant protein was eluted from the resin with $0.2 \mathrm{M}$ Na-acetate/saline, $\mathrm{pH}$ 4.0. Protein concentrations were determined by BCA protein assay reagent (Pierce, Rockford, IL, U.S.A.) using bovine serum albumin as the standard. The amino acid sequence of the amino-terminus of $\mathrm{YMSPI}_{19}$ was determined by automated Edman degradation (Biological Resources Branch, National Institute of Allergy and Infectious Diseases).

\section{DNA Sequence and DNA Fingerprinting Analyses}

The DNA sequences of the coding regions of all expression constructs were determined from double-stranded plasmids using USB Sequenase version 2.0 (USB, Cleveland, OH, U.S.A.). To determine whether the $\mathrm{MSPl}_{19}$ DNA sequence of the parasites recovered from Monkey 1193 on the day of treatment was identical to that of the FVO parasite used for inoculation, the $\mathrm{MSPl}_{42}$ region was PCR-amplified from genomic DNA. The PCR-amplified fragment was cloned into the $P v u I I$ and ApaI restriction sites of plasmid vector pRE4 and sequenced as described above. Fingerprint analysis of genomic DNA was performed as previously described (12).

\section{Enzyme-Linked Immunosorbent Assay, Western Blot Analysis, and Immunofluorescence}

For enzyme-linked immunosorbent assay (ELISA), 96-well plates were coated overnight at $4^{\circ} \mathrm{C}$ with 1 $\mu \mathrm{g} / \mathrm{ml}$ of $\mathrm{yMSP}_{19}$. The plates were blocked with TPBS ( $1 \times$ PBS and $0.05 \%$ Tween 20$)$ and $1 \%$ BSA for $1 \mathrm{hr}$ at $37^{\circ} \mathrm{C}$. Log-fold dilutions of test Aotus sera (taken on Day 17 after the third immunization) in TPBS with $0.5 \%$ BSA were used as primary antibodies. Alkaline phosphatase-conjugated goat anti-human immunoglobulin (IgG) (Promega, Madison, WI, U.S.A.) was used as a secondary antibody. The ELISA end-point titer reported is the highest dilution at which the absorbance at $405 \mathrm{~nm}$ was 0.4 or greater.

For Western blot analysis, protein samples were size-fractionated on $4-16 \%$ SDS-PAGE
(ISS, Natick, MA, U.S.A.), electrophoretically transferred to nitrocellulose membranes, and then incubated with anti-MSP1 19 mAbs 111.2 and 111.4 (3) and alkaline phosphatase-conjugated goat anti-mouse IgG (Promega) as secondary antibody. The protein bands were visualized by incubation with NBT/BCIP (Promega).

Immunofluorescence (IIF) was performed with methanol-fixed $P$. falciparum parasites of the FCRIII strain (FCRIII is similar to FVO in the 19-kD carboxy-terminus by allelic-specific oligonucleotide (ASO) PCR; S. Kumar and D. C. Kaslow, unpublished data). Briefly, air-dried parasites on toxoplasmosis slides (Bellco Glass, Inc., Vineland, NJ, U.S.A.) were fixed with dryice cold methanol for $15 \mathrm{~min}$, washed twice with PBS, and blocked for $30 \mathrm{~min}$ with $1 \%$ BSA in PBS, then incubated with dilutions of Aotus sera (taken on Day 17 after the third immunization) for $30 \mathrm{~min}$ at room temperature in a humid chamber. After washing with PBS, FITC-conjugated sheep anti-human IgG (Becton-Dickinson, San José, CA, U.S.A.) was added to wells for 30 $\mathrm{min}$. The slides were read by fluorescent light microscopy. The immunofluorescence was evaluated using a Zeiss Axiophot microscope equipped with differential interference contrast (DIC) optics.

\section{Immunization and Parasite Challenge of Aotus Monkeys}

Twelve Aotus monkeys of two species (seven $A$. nancymai and five $A$. vociferans) and of both sexes were used in the study (Table 1). The monkeys were housed at the National Institutes of Health, Primate Research Facility, according to Guide for the Care and Use of Laboratory Animals, NIH. After stratification for sex and species, the monkeys were assigned to groups by random card draw. The study was blinded to investigators who cared for or injected the animals, read smears, or determined when a monkey should be drug-cured; only after all control monkeys required treatment (Day 20) was the code revealed. Three groups of four monkeys each were immunized with yMSP1 ${ }_{19}$, bMSP $_{42}$, or Freund's adjuvant alone. Monkeys from the two test vaccine groups received $250 \mu \mathrm{g}$ of the respective recombinant protein. On Day 0, the first dose was emulsified in complete Freund's adjuvant and given subcutaneously in equal volumes at four sites. Two subsequent doses, emulsified in incomplete Freund's Adjuvant, were also given subcutaneously at four sites on Days 21 and 42. Blood for 
serum was obtained from each monkey on Days $0,21,42$, and 59 .

After inoculating Monkey 1588 with freshly thawed $P$. falciparum parasites of the FVO strain (kindly provided by Dr. W. E. Collins, CDC), a frozen stock of FVO challenge parasites was prepared. On Day 11 after the third immunization, a donor monkey (No. T64) randomly selected from the control group by the investigator holding the code was infected intravenously with approximately $10^{6}$ freshly thawed $P$. falciparum parasites from Monkey 1588. Six days later, blood collected from Monkey T64 was diluted in phosphate buffered saline to $2 \times 10^{4}$ parasitized red blood cells (PRBCs) $/ \mathrm{ml}$, and monkeys from all the groups were challenged intravenously with $0.5 \mathrm{ml}$ of the diluted PRBCs. The challenge infection was on Day 59 after beginning of immunization and Day 17 after the last immunization.

Giemsa-stained thin smears were made from blood collected by puncture of superficial veins in the dorsum of the calf. For parasitemias of less than $0.1 \%$, parasite numbers in approximately 10,000 RBCs (50 fields) were counted. For parasitemias of more than $0.1 \%$, parasite numbers in 500-1000 RBCs were counted. Blood smears were taken daily from each monkey from Day 3 to Day 28 after challenge and then twice a week for 60 days unless the monkey received chemotherapy.

\section{Inhibition of Erythrocyte Invasion In Vitro}

To determine if immunization with recombinant MSPl-induced antibodies blocked invasion of merozoites into RBCs, synchronized $P$. falciparum parasites from in vitro culture were incubated in the presence of sera taken from Aotus monkeys on Day 17 after the third immunization (day of parasite challenge). To ensure synchrony, the FCRIII strain of $P$. falciparum was used $24 \mathrm{hr}$ after thawing the parasites frozen in liquid nitrogen. A mixture of trophozoites and schizonts was diluted to about $0.2 \%$ PRBCs with a hematocrit of $5 \%$ human RBCs in RPMI medium containing $10 \%$ human serum and $8 \mu \mathrm{g} / \mathrm{ml}$ of gentamicin. One hundred microliters of the mixture of parasitized and uninfected human RBCs and $100 \mu \mathrm{l}$ of RPMI medium $+20 \%$ serum $(10 \%$ human serum $+10 \%$ Aotus test serum taken on Day 17 after the third immunization) were added to wells of a 96-well plate. The plate was placed in a gas-tight chamber, equilibrated with $5 \% \mathrm{O}_{2}$, $5 \% \mathrm{CO}_{2}$, and $90 \% \mathrm{~N}_{2}$ for $10 \mathrm{~min}$, sealed, and incubated at $37^{\circ} \mathrm{C}$. After $22-24 \mathrm{hr}$, the contents of the duplicate wells were collected and centrifuged. Air-dried blood films of each sample were fixed with methanol and Giemsa stained. The samples were coded, and the number of ringstage parasites in 1500-4000 RBCs was counted.

\section{RESULTS AND DISCUSSION}

The $P$. falciparum parasite used in these studies was the Aotus monkey-adapted FVO strain. Intravenous inoculation of asexual blood-stage FVO parasites in nonsplenectomized $A$. nancymai causes fulminant infections that are uniformly fatal if untreated (13). Because of the limited availability of nonhuman primates for trials of malaria parasite vaccines, the consistent infectivity of this FVO parasite-Aotus model allows preliminary assessment of in vivo efficacy of bloodstage vaccine candidates in test groups of small numbers of monkeys.

To express $\mathrm{MSP}_{19}$ as a secreted fusion protein in S. cerevisiae, the carboxy-terminus of yeast $\alpha$-factor preprosecretory signal sequence was fused to two helper $\mathrm{T}$ cell epitopes from tetanus toxoid (P30 and P2) that, in turn, were fused to the amino-terminus of $\mathrm{MSP}_{19}$. A $\mathrm{His}_{6}$ tag was added to the carboxy-terminus to facilitate purification. Although an apparent full-length P30P2 MSPI $_{19}$ was observed on a Coomassie-stained SDS-PAGE, most of the secreted fusion protein was cleaved (data not shown). Automated Edman degradation revealed that approximately $80 \%$ of the nickel-NTA-purified proteins had at the amino-terminus the three carboxy-terminal amino acid residues, EVE, of the P30P2 sequence followed by the $\mathrm{MSP}_{19}$ amino-terminus, NISQHQPVQHQ-,indicating that the P30P2 fusion had been cleaved from $\mathrm{MSPl}_{19}$. Mass spectroscopy confirmed that observed mass $\left(M_{r}\right.$ of $\left.11,475.4\right)$ of the predominant protein species was similar to that predicted $\left(M_{r}\right.$ of 11,523$)$ for the polypeptide $\mathrm{NH}_{2}$-EVENISQHQ FDGIFC$\mathrm{SHHHHHH-COOH}$. Although full-length or truncated forms of P30P2 $\mathrm{MSP}_{19}$ could be present in the preparation used for immunizations, the predominant immunogen used in these studies

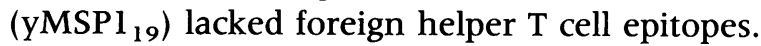
The other fusion protein, $\mathrm{bMSP}_{42}$, designed to be expressed intracellularly in $E$. coli, was constructed with glutathione-S-transferase (GST) from $S$. mansoni fused to the amino-terminus of $\mathrm{MSP}_{42}$. Both $\mathrm{yMSP}_{19}$ and $\mathrm{bMSP} \mathrm{l}_{42}$ proteins were recognized in ELISA and on Western blot by 
TABLE 1. The Relation Between the Course of Infection in Vaccinated Aotus Monkeys and Neutralization of Invasion and Other Serologic Studies

\begin{tabular}{|c|c|c|c|c|c|c|c|c|}
\hline \multirow[b]{2}{*}{ Vaccine $^{a}$} & \multicolumn{3}{|c|}{ Monkeys $^{b}$} & \multirow{2}{*}{$\begin{array}{c}\text { Prepatent } \\
\text { Period }^{c} \\
\text { (days) }\end{array}$} & \multirow[b]{2}{*}{ Course $^{d}$} & \multirow{2}{*}{$\begin{array}{c}\text { Invasion }^{e} \\
\text { (\% Infected } \\
\text { RBCs) }\end{array}$} & \multirow[b]{2}{*}{$\mathbf{I I F}^{f}$} & \multirow[b]{2}{*}{ ELISA $^{g}$} \\
\hline & $\#$ & Sex & Species & & & & & \\
\hline \multirow[t]{3}{*}{ Freund's alone } & 701 & Male & $\mathrm{N}$ & 9 & Virulent & 1.5 & $<10^{2}$ & $<10^{2}$ \\
\hline & 886 & Female & $\mathrm{N}$ & 12 & Virulent & 1.7 & $<10^{2}$ & $<10^{2}$ \\
\hline & 184 & Male & $\mathrm{V}$ & 7 & Virulent & 1.3 & $<10^{2}$ & $<10^{2}$ \\
\hline \multirow[t]{4}{*}{$\mathrm{yMSP}_{19}$} & $331 \mathrm{~A}$ & Male & $\mathrm{N}$ & 11 & Self-resolved & 1.6 & $10^{4}$ & $10^{6}$ \\
\hline & 218 & Female & $\mathrm{N}$ & 12 & Self-resolved & 1.6 & $10^{4}$ & $10^{5}$ \\
\hline & 1193 & Male & $\mathrm{V}$ & 28 & Virulent & 1.7 & $>10^{5}$ & $10^{6}$ \\
\hline & 2458 & Male & $\mathrm{V}$ & 11 & Virulent & 2.1 & $10^{4}$ & $10^{6}$ \\
\hline \multirow[t]{3}{*}{ bGST-MSPl ${ }_{42}$} & 202 & Male & $\mathrm{N}$ & 10 & Virulent & ND & $10^{3}$ & $10^{3}$ \\
\hline & E851 & Male & $\mathrm{N}$ & 11 & Persistent & ND & $10^{3}$ & $10^{4}$ \\
\hline & $\mathrm{T} 212$ & Male & $\mathrm{V}$ & 8 & Virulent & ND & $10^{4}$ & $10^{4}$ \\
\hline
\end{tabular}

${ }^{a} \mathrm{YMSPl}_{19}$, yeast produced fusion of the 19-kD C-terminus of MSP1 ${ }_{19} ;$ GST-MSP1 ${ }_{42}$, bacterial produced 42-kD C-terminus of MSP1 fused with glutathione-S-transferase.

${ }^{b}$ Species of Aotus: N, A. nancymai; V, A. vociferans.

${ }^{c}$ Prepatent period: time from inoculation of parasites to first visualized parasite in the blood.

${ }^{d}$ Virulent, rose to above $5 \%$, requiring treatment; self-resolved, after a low-grade parasitemia of $<0.1 \%$; Persistent, no control, but parasitemia always below $5 \%$.

${ }^{e}$ Percentage of red cells that contained ring-stage parasites in the invasion assay performed in the presence of Aotus sera from Day 17 after the third immunization (the day of parasite challenge).

${ }^{f}$ IIF, indirect immunofluorescence against FCRIII that has the identical C-terminus as the FVO strain of $P$. falciparum.

${ }^{g}$ ELISA, enzyme-linked immunosorbent assay. End-point titers defined as the highest dilution of sera with an $\mathrm{A}_{405}$ of 0.4 or greater (data from three different assays).

mAbs 111.2 and 111.4 that recognize reductionsensitive epitopes of $\mathrm{MSPI}_{19}$ (data not shown).

Because of limited availability in our colony of a single species of Aotus, two species of monkeys (seven $A$. nancymai and five $A$. vociferans) were used (Table 1). They were stratified according to species and sex and randomized to one of three groups: four test monkeys received $\mathrm{yMSP}_{19}$ emulsified in Freund's adjuvant; four test monkeys received $b M S P 1_{42}$ fusion protein in the same adjuvant; and four control monkeys received adjuvant alone. In the first immunization, the adjuvant was Complete Freund's adjuvant, and the subsequent injections on Days 21 and 42 were with incomplete Freund's adjuvant. Seventeen days after the third immunization, the monkeys were inoculated intravenously with $10^{4}$ parasites of the FVO isolate of $P$. falciparum to assess the in vivo efficacy of vaccination. The three control monkeys became parasitemic by Day 12 postchallenge and were treated with antimalarial medications on or before Day 19
(Fig. $\mathrm{l} \mathrm{E}$ and F). The course of parasitemia in these animals was similar to that previously observed in $A$. nancymai monkeys infected with the FVO strain of $P$. falciparum (13). In the group of four monkeys immunized with $\mathrm{bMSP}_{42}$, one monkey died after the first immunization. Upon challenge infection, A. nancymai (202) and $A$. vociferans (T212) were unprotected, and one $A$. nancymai (E851) controlled the initial peaks of parasitemia (Fig. $1 \mathrm{C}$ and D). Monkey E851 had no detectable parasites from Day 18 through Day 22 , but eventually developed a $1 \%$ parasitemia on Day 28 and required chemotherapy because of severe anemia.

The two $A$. vociferans immunized with $\mathrm{YMSPl}_{19}$ were not protected (Fig. 1B). A. vociferans 2458 had the same course as control monkeys, having detectable parasitemia on Day 11 and requiring chemotherapy on Day 14. A. vociferans 1193 had no detectable parasitemia for 28 days, but on Day 32 the parasitemia was $4 \%$ and rapidly rose such that Monkey 1193 required treatment on Day 34 

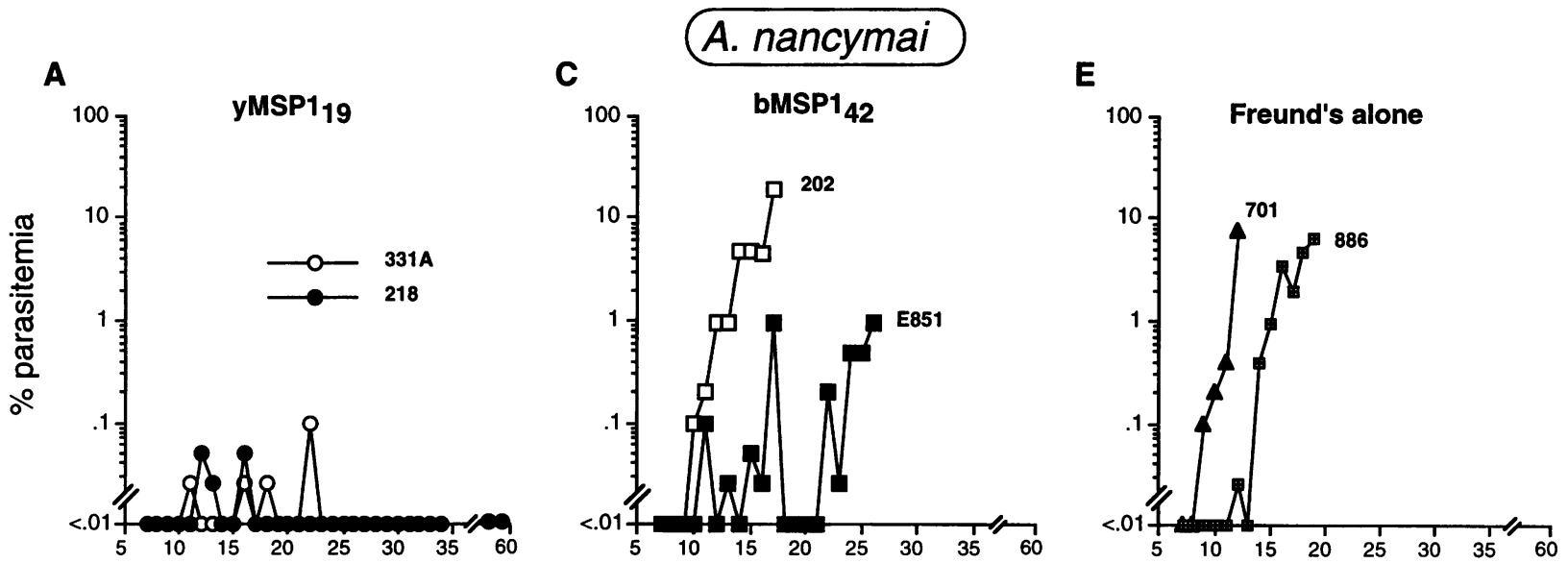

\section{A. vociferans}
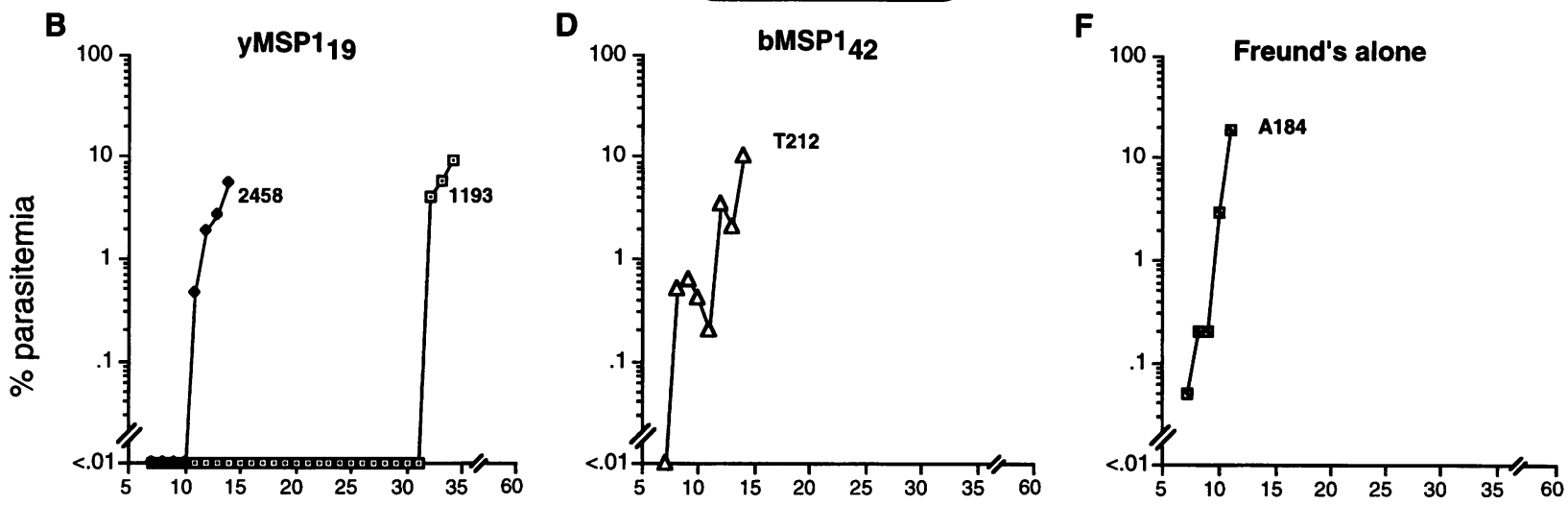

\section{Days after infection}

FIG. 1. Parasitemia curves for infections of the Vietnam Oak Knoll (FVO) strain of Plasmodium falciparum in Aotus nancymai or $A$. vociferans monkeys immunized with YMSP1 19 (A and B), bMSPI 42 (C and $D)$, or adjuvant alone ( $E$ and $F$ )

(Fig. 1B). It is possible that the parasites that emerged after this prolonged prepatent period had a variant form of MSP1. Diversity in the single-copy $M S P 1_{19}$ gene sequence (14) and in the reactivity of MSPl with mAbs has been observed (15). Such vaccine-selected mutations have been described previously for other asexual blood-stage proteins (16). DNA fingerprints from the original inoculum and from the parasites isolated on Day 34 were identical (data not shown), indicating that the major clone in the inoculum caused the latent infection. To explore the possibility of mutations in $\mathrm{MSPl}_{19}$, we compared the MSP $_{19}$ DNA sequence of the original inoculum to that of recovered parasites. The DNA sequences were identical. Therefore, neither emergence of a minor clone nor selection of a $\mathrm{MSP}_{19}$ mutant explains the prolonged prepatent period in Monkey 1193. Another possibility is that Monkey 1193 selected parasites expressing abnormal levels of $\mathrm{MSP}_{19}$ as a result of a mutation outside the coding region for $\mathrm{MSPl}_{19}$ (e.g., a mutation elsewhere in the coding region or the MSP1 promoter). By immunofluorescence assay and immunoblot analysis, two anti-MSP1 19 mAbs, 111.2 and 111.4 , reacted similarly with the inoculum parasites and the parasites recovered from Monkey 1193, confirming that the subcellular location (rim fluorescence suggestive of surface location) and the level of expression of MSP $_{19}$ were unchanged in the recovered parasites (data not shown).

The two $A$. nancymai monkeys vaccinated with $\mathrm{YMSP}_{19}$ (331A and 218) had peak parasitemias of $<0.1 \%$ and self-cured their infections (Fig. 1A). Before becoming completely apara- 
sitemic, these monkeys had one to three recurrences of detectable parasitemia at intervals of up to 5 days. Because RBCs infected with mature parasites bind endothelium, a fall in parasitemia may occur $24 \mathrm{hr}$ after a peak. These sequestered parasites develop into merozoites, invade uninfected RBCs, and reappear in the peripheral blood $48 \mathrm{hr}$ after the previous peak. In the absence of immunity, each subsequent peak of parasitemia should increase. Such a course of parasitemia was observed in control A. nancymai 886 from Day 12 to Day 14 (Fig. 1E). The course of parasitemia in protected animals was different in that the detectable parasitemias recurred at intervals of up to 5 days, and the parasitemia during the recurrence was similar to the previous peak. Therefore, immunity controlled the infection.

What, then, might be the mechanism of antigen-specific immunity in A. nancymai $331 \mathrm{~A}$ and 218? Analysis of in vitro invasion inhibition assays indicated that sera from monkeys that selfresolved infections did not inhibit invasion of uninfected RBCs by merozoites (Table 1). These data suggest that the mechanism of protective immunity is not mediated solely by neutralizing antibodies that prevent parasites from invading erythrocytes. Further evidence that clearance of parasites is not entirely dependent on blocking antibodies comes from analysis of the kinetics of parasitemia in monkeys that self-resolved infections. If the control of the initial peak was caused by boosting of blocking antibody by infection, then recurrences should not have occurred a few days later.

The most likely explanation is that a recurring immune response is activated during each rise in parasitemia and declines as the parasitemia falls. One such mechanism has been proposed by Druilhe et al. to explain antibody-mediated immunity. In their study, IgG from immune African donors-when transferred to $P$. falciparum-infected Thai patients-controlled infection (17); however, the immune IgG did not block $P$. falciparum invasion of RBCs in vitro but did inhibit parasite development when parasites were cultured in the presence of monocytes. It has been proposed that cytophilic antibodies to parasite membrane proteins bind Fc receptors on monocytes, which leads to a transient release of cytokines that inhibit parasite growth. Such a mechanism is consistent with our finding of recurrence of parasitemia in the protected monkeys.

It remains to be determined whether antibody-independent, $\mathrm{T}$ cell-mediated mechanisms also contributed to immunity. The notion of cell- mediated immunity was suggested in the initial murine immunization studies using purified Plasmodium yoelii MSP1 (18-20). Transfer of sera from immune mice did not transfer protection; rather, protection was correlated with delayedtype hypersensitivity to malaria parasites (20). However, antibody from mice immunized with a MSP-1 construct similar to the one used in the present study did transfer protection in a rodent malaria, P. yoelii (C. A. Long, personal communication). The MSP-1 vaccine in this rodent model was previously shown to give a high level of protection, indicating that the protection is at least in part antibody-mediated (6).

In previous studies, the FVO strain of $P$. falciparum caused a universally virulent infection in A. nancymai (Ref. 13 and S. Kumar, unpublished observations). That two of two A. nancymai were highly protected (maximum parasitemia of $0.1 \%$ ) in the present study suggests that immunization with $\mathrm{MSPI}_{19}$ induces an effective immune response. The virulent course we observed in $A$. vociferans after immunization with YMSP1 19 may reflect the fact that this species of Aotus, for unknown reasons, is more susceptible to infection by $P$. falciparum. For example, several strains of $P$. falciparum (FUP, Malay IV, Indochina, and FVO) follow a virulent course in $A$. vociferans, but only FVO is consistently virulent in A. nancymai (Ref. 13 and W. E. Collins, personal communication). The difference in parasitemia does not reflect failure to induce antibody, as $A$. vociferans and $A$. nancymai had similar anti-MSP $1_{19}$ titers by ELISA and similar IIF titers (Table 1).

In contrast to $A$. vociferans, $A$. nancymai appears to be a useful model for initial screening and testing of $P$. falciparum (FVO) asexual bloodstage vaccines. Using this model, $\mathrm{yMSP}_{19}$ is a promising vaccine candidate. Further studies in the FVO-A. nancymai model may help elucidate the relative contribution of antibodies, cellular responses, and cytokines in protective immunity induced by vaccination with $\mathrm{MSPI}_{19}$.

\section{ACKNOWLEDGMENTS}

We thank William E. Collins for providing FVO parasites, Ginny Price for the yeast expression vector, John Coligan for $\mathrm{N}$-terminal sequence and mass spectroscopy analyses, Jim Dvorak for helping with fluorescent microscopy, Francoise Guinet for fingerprint analysis, and Lynn Lambert and Charles D. Hatcherson for technical support in handling animals. 


\section{REFERENCES}

1. Diggs CL, Ballou WR, Miller LH. (1993) The major merozoite surface protein as a malaria vaccine target. Parasitol. Today 9: 300-302.

2. Holder AA, Freeman RR. (1984) The three major antigens on the surface of Plasmodium falciparum merozoites are derived from a single high molecular weight precursor. J. Exp. Med. 160: 624-629.

3. Holder AA, Lockyer MJ, Odnik KG, et al. (1985) Primary structure of the precursor to the three major surface antigens of Plasmodium falciparum merozoites. Nature 317: 270-273.

4. Blackman MJ, Heidrich H-G, Donachie S, McBride JS, Holder AA. (1990) A single fragment of a malaria merozoite surface protein remains on the parasite during red cell invasion and is the target of invasion-inhibiting antibodies. J. Exp. Med. 172: 379-382.

5. Blackman MJ, Ling IT, Nicholls SC, Holder AA. (1991) Proteolytic processing of Plasmodium falciparum merozoite surface protein-1 produces a membrane-bound fragment containing two epidermal growth factor-like domains. Mol. Biochem. Parasitol. 49: 29-34.

6. Daly TM, Long C. (1993) A recombinant 15kilodalton carboxy-terminal fragment of Plasmodium yoelii yoelii 17XL merozoite surface protein 1 induces a protective immune response in mice. Infect. Immun. 61: 24622467.

7. Ling IT, Ogun SA, Holder AA. (1994) Immunization against malaria with a recombinant protein. Parasitol. Immunol. 16: 63-67.

8. Chang SP, Gibson HL, Lee-Ng CT, Barr PJ, Hui GSN. (1992) A carboxyl-terminal fragment of Plasmodium falciparum gp195 expressed by a recombinant baculovirus induces antibodies that completely inhibit parasite growth. J. Immunol. 149: 548-555.

9. Valmori D, Pessi A, Bianchi E, Corradin G. (1992) Use of human universally antigenic tetanus toxin $\mathrm{T}$ cell epitopes as carriers for human vaccination. J. Immunol. 149: 717-721.

10. Price V, Mochizuki D, March CJ, et al. (1987) Expression, purification and characterization of recombinant murine granulocyte-macrophage-colony-stimulating factor and bovine interleukin-2 from yeast. Gene 55: 287-293.

11. Kaslow DC, Shiloach J. (1994) Production, purification and immunogenicity of a malaria transmission-blocking vaccine candidate: TBV25H expressed in yeast and purified using nickel-NTA agarose. Biotechnology 12: 494-499.

12. Dolan SA, Herrfeldt JA, Wellems TE. (1993) Restriction polymorphisms and fingerprint patterns from an interspersed repetitive element of Plasmodium falciparum DNA. Mol. Biol. Parasitol. 61: 137-142.

13. Collins W, Galland GG, Sullivan JS, Morris CL. (1994) Selection of different strains of Plasmodium falciparum for testing blood-stage vaccines in Aotus nancymai monkeys. Am. J. Trop. Med. Hyg. 51: 224-232.

14. Miller LH, Roberts T, Shahabuddin $M$, McCutchan TF. (1993) Analysis of sequence diversity in the Plasmodium falciparum merozoite surface protein-1 (MSP-1). Mol. Biochem. Parasitol. 59: 1-14.

15. Kaslow DC, Hui G, Kumar S. (1994) Expression and antigenicity of Plasmodium falciparum major surface protein $\left(\mathrm{MSP}_{19}\right)$ variants secreted from Saccharomyces cerevisiae. Mol. Biol. Parasitol. 63: 283-289.

16. Hudson D, Wellems TE, Miller LH. (1988) Molecular basis for mutation in a surface protein expressed by malaria parasites. $J$. Mol. Biol. 203: 707-714.

17. Bouaroum-Tayoum H, Attanath P, Sabchareon A, Chongsuphajaisiddhi T, Druilhe P. (1990) Antibodies that protect humans against Plasmodium falciparum blood stages do not on their own inhibit parasite growth and invasion in vitro, but act in cooperation with monocytes. J. Exp. Med. 172: 1633-1641.

18. Holder AA, Freeman RR. (1981) Immunization against blood-stage rodent malaria using purified parasite antigens. Nature 294: 361-364.

19. Freeman RR, Holder AA. (1983) Characteristics of the protective response of BALB/C mice immunized with a purified Plasmodium yoelii schizont antigen. Clin. Exp. Immunol. 54: 609-616.

20. Playfair JHL, De Souza JB, Freeman RR, Holder AA. (1985) Vaccination with a purified blood-stage malaria antigen in mice: correlation of protection and T cell mediated immunity. Clin. Exp. Immunol. 62: 19-23. 